$\$$ Research Square

\title{
Detection Molecular of Leishmania Spp. And Blood Source in Female Sand Flies in the Parque Estadual Do Rio Doce and in the Municipality of Timóteo, Minas Gerais, Brazil.
}

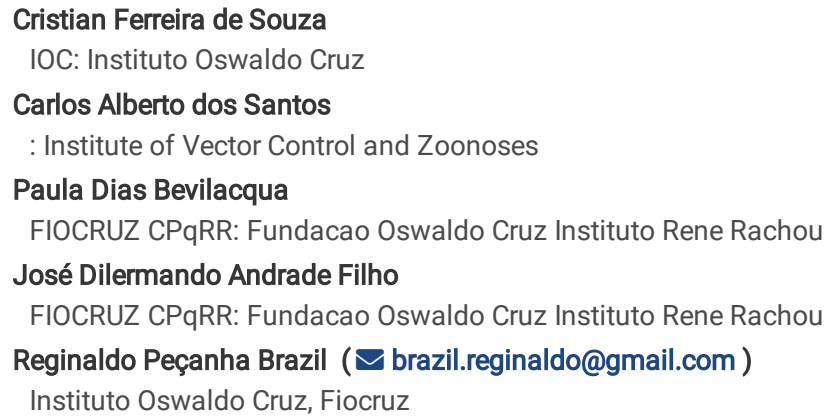




\section{Abstract}

Background: Leishmaniasis is a set of diseases caused by protozoa of the Leishmania genus (Kinetoplastida: Trypanosomatidae) and transmitted by the bite of female sand fly insects (Diptera: Psychodidae). The present work was characterized as a descriptive study comparing two areas: a wild area where the Parque Estadual do Rio Doce (PERD) is located and another urban area, located in the municipality of Timóteo-MG (AUT). Aiming to identify the presence of Leishmania spp. and the blood source of collected female sand flies.

Methods: Sand flies were collected with CDC light trap model HP, between September 2012 and February 2014. We used 19 traps in the Urban Area of Timóteo and 12 in the Rio Doce State Park. For molecular studies of Leishmania spp. DNA we used ITS1 gene and in the search of blood source, with naturally fed females, the CytB gene was used and positive samples were sequenced.

Results: It was clear that in the municipality of Timóteo there are at least three species of Leishmania: Leishmania (Viannia) braziliensis, Leishmania (Leishmania) amazonensis and Leishmania (V.) guyanensis. A large presence of Leishmania braziliensis DNA was identified in female sand flies. Nyssomyia whitmani was the most captured species in the urban area, while in the PERD it was Pressatia choti, both species were positive for the presence of Leishmania braziliensis DNA. And last but not least was the record of the participation of Gallus gallus (chicken) and Sus scrofa (pig) as a blood source for sandflies, which helps to maintain the life cycle of vectors in the urban area of the municipality.

Conclusion: The present study demonstrates that Leishmania braziliensis is the main tegumentary leishmaniasis transmitter agent in the study area, with effective participation of Nyssomyia whitmani as a vector. And it draws attention to the possibility that Gallus gallus (chicken) and Sus scrofa (pig) are fundamental in maintaining the cycle in urban areas.

\section{Introduction}

Leishmaniasis are enzootic and zoonotic diseases caused by morphologically similar parasitic protozoa of the genus Leishmania (Kinetoplastida: Trypanosomatidae) and transmitted by the bite of female insects called sand flies (Diptera: Psychodidae) [1]. In 2018,92 and 83 countries or territories were considered endemic or had already reported cases of tegumentary leishmaniasis (TL) and visceral leishmaniasis (VL), respectively. It is estimated that more than 1 billion people live in endemic areas for leishmaniasis and are at risk of infection, and that 30,000 new cases of VL and more than 1 million new cases of TL occur annually [2].

Data from WHO (2021) [2] showed that in 2019 Brazil was one of the countries with the highest number of cases of VL and TL worldwide. Between 2010 and 2019 Brazil presented an annual average of 20,106 cases of TL and 3,643 cases of VL notified. In the state of Minas Gerais, in the same period, 4,919 cases of $\mathrm{VL}$ and 15,134 cases of TL were registered, with an average annual incidence of 7.4/100,000 inhabitants for TL and 2.4/100,000 inhabitants for VL [3,4]. In the municipality of Timoteo, 229 cases of TL were registered in the period 2001 to 2019 and the first reported case of VL was in 2006 , reaching a total of 21 cases in the municipality by 2019 [3].

Regarding this municipality, species incriminated as vectors of Leishmania have already been recorded, both in the wild (Parque Estadual do Rio Doce PERD) [5], 2015) and in the urban area [6-9]. The main species recorded were Lutzomyia longipalpis, Nyssomyia intermedia, Nyssomyia whitmani and Migonemyia migonei. Although possible vector species are known, nothing is known about the species of the parasite that may be circulating in the municipality of Timóteo and not even the possible sources of blood for female sand flies.

In this sense, we determined, through molecular techniques, the blood source of naturally fed female sand flies, as well as identifying the Leishmania species that can participate in the transmission cycle in the municipality of Timóteo and thus subsidize more effective prevention and control actions by health agencies.

\section{Materials And Methods}

\subsection{Characterization of the study area}

The study was carried out in the urban area of the municipality of Timóteo (AUT) (19³4'58"S; 42³8'38"W) and in a wild area, Parque Estadual do Rio Doce (PERD). The municipality of Timóteo is located in the Metropolitan Region of Vale do Aço, in the state of Minas Gerais, with a land area of 145,159 km² and

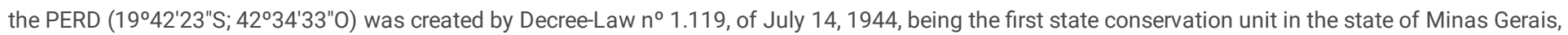
inserted between the municipalities of Timóteo, Marliéria, Dionísio. One of the largest Atlantic Forest conservation areas in Brazil, with 35,976 hectares[4].

\subsection{Capture of sand flies}

The sand flies collected at the AUT were captured in the peridomicile of 19 homes with notification of human cases of leishmaniasis (unpublished data). In the PERD area, collections were carried out on the Juquita Trail, a trail close to the city's urban area. Twelve traps were distributed along the Trail with a distance of approximately 300 meters between them, as described by Souza et al., (2015) [5] (Fig. 1).

In the capture of sand flies, a CDC light trap model HP, was used between Sep/2012-Feb/2014. The traps were exposed for two consecutive nights (06:00pm to 06:00am), with monthly collections, both in the peridomicile environment, in the municipality of Timóteo, and in the wild areas located in the PERD.

\subsection{Identification of sand flies}


The captured insects were killed in a refrigerated chamber for material screening. All males and a part of collected females were mounted on slides and coverslips and identified. Part of the females was dissected and the head and last segments of the abdomen were used for identification. The rest of the female body (abdomen, thorax) was used for molecular studies. In females that had no blood meal, the presence of Leishmania spp. DNA was verified, whereas in fed females, a study was carried out to identify the blood source.

The idenfication of species collected in the urban area of Timóteo followed the classification of Galati (2003) [10] and the list of species collected in the PERD can be found in Souza et al. (2015) [5]. The abbreviation of species names was according to Marcondes (2007) [11].

\subsection{DNA extraction}

Female sand flies were individually identified and stored in $1.5 \mathrm{ml}$ polypropylene microtubes with 6\% DMSO and used for DNA extraction using a commercial Gentra Puregene ${ }^{\circledR}$ Cell and Tissue Extraction Kit (QIAGEN, Hilden, Germany) following the manufacturer's protocol.

The extracted DNA was resuspended in $20 \mu \mathrm{l}$ in rehydration solution and the microtubes were preserved at $-20^{\circ} \mathrm{C}$. The total DNA samples extracted from female sand flies reached an average final concentration of $6 \mathrm{ng} / \mu \mathrm{l}$.

\subsection{Detection of Leishmania spp. DNA}

The extracted DNA was submitted to the PCR technique for amplification of a target region of the DNA of Leishmania spp., the ITS1 (internal transcribed spacer 1) (LITSR 5' CTGGATCATTTTCCGATG 3' and L5.8S 5' TGATACCACTTATCGCACTT 3') [12].

In the PCR, the amplification of a fragment of approximately 350bp was carried out using the following reaction: $1 \mathrm{x}$ buffer solution (200 mM Tris-HCl pH8.4, $500 \mathrm{mM} \mathrm{KCl}$ ), $1.5 \mathrm{mM} \mathrm{MgCl} 2,0.2 \mathrm{mM}$ dNTPs mixture, 0.5 pmol of LITSR primer, 0.5 pmol of L5.8S primer, 1 U of Taq DNA Polymerase Platinum ${ }^{\circledR}$ (Invitrogen, California, USA) and $5 \mu$ l of template DNA, in a final volume of $25 \mu \mathrm{L}$. Amplification was performed alternating 33 cycles of denaturation at $95^{\circ} \mathrm{C}$ for 30 sec, annealing at $53^{\circ} \mathrm{C}$ for $1 \mathrm{~min}$ and extension at $72^{\circ} \mathrm{C}$ for $1 \mathrm{~min}$ in an automatic DNA thermocycler equipment (MaxyGene Gradient - AXYGENE ${ }^{\text {, }}$ Corning, USA). The amplified band profiles were analyzed on a $2 \%$ agarose gel stained with GelRed ${ }^{\text {TM }}$ (Nucleic Acid Gel Stain - Biotium, Fremont, USA), concentration used: GelRed 10.000X in 500 $\mu$ l of contamination-free water (1:500), was applied $1 \mu$ l of diluted GelRed ${ }^{\text {TM }}, 1 \mu$ l of loading buffer and $5 \mu$ l of amplified PCR product, and compared to PCR product from reference strains of Leishmania braziliensis (MHOM/BR/75/M2903). DNA from male sand flies were used as negative controls.

The PCR/ITS1 positive samples were cloned by bacterial transformation, using the Escherichia coli species (DH5-a) as competent bacteria cells and for the ligation reaction the commercial CloneJet PCR Kit (Thermo Scientific, California, USA) was used, the preparation of the reaction followed the manufacturer's protocol. Cloning was necessary to increase the amount of DNA amplified in PCR/ITS1 and subsequent sequencing of the samples.

\subsection{Study of blood source}

The DNA of female sand flies with signs of blood meal in their abdomen were analyzed by PCR and sequenced. The Cytochrome $B$ (CytB) gene was used in the PCR (FOR5' - CCATCCAACATCTCAGCATGATGAAA - 3' and REV5' - GCCCCTCAGAATGATATTTGTCCTCA - 3') [13]. The DNA was subjected to PCR in a 1X buffer solution (200 mM Tris-HCl pH8.4, $500 \mathrm{mM} \mathrm{KCl),} 1.5 \mathrm{mM} \mathrm{MgCl} 2,0.2 \mathrm{mM}$ dNTPs mix, 0.5 pmol of CytB FOR5 primers ' and REV5", 1 U of platinum ${ }^{\circledR}$ Taq DNA polymerase (Invitrogen) and $5 \mu$ l of template DNA, in a final volume of $50 \mu$ l. Amplification was performed alternating 32 cycles of denaturation at $95^{\circ} \mathrm{C}$ for $20 \mathrm{sec}$, annealing at $53^{\circ} \mathrm{C}$ for $30 \mathrm{sec}$ and extension at $72^{\circ} \mathrm{C}$ for $1 \mathrm{~min}$ in an automatic DNA thermocycler equipment (MaxyGene Gradient - AXYGENE $\AA$ ). The amplified band profile was analyzed on a $2 \%$ agarose gel stained with GelRed ${ }^{\mathrm{T}} \mathrm{\text { }}$, concentration used: GelRed $10.000 \mathrm{X}$ in $500 \mu \mathrm{l}$ of contamination free water (1:500), $1 \mu$ l of diluted GelRed ${ }^{\text {TM }}$ was applied, $1 \mu$ l of loading buffer and $5 \mu$ l of amplified product in the PCR, and compared to amplified samples of DNA extraction from dog and rodent blood as a positive control. The material amplified in the CytB PCR was sequenced.

\subsection{Sequencing}

All samples that had amplified PCR product, both in the DNA detection study and in the blood source study, were sent for sequencing to the Macrogen ${ }^{\circledR}$ company (South Korea), where the automatic sequencer (Applied Biosystems 3730XL) was used. Each sample had its DNA sequenced in both directions. The sequences obtained were aligned and edited using the Sequencher® 4.1.4 program and compared using the Blast algorithm (Basic Local Alignment Search Tool) with sequences available in GenBank.

\subsection{Data analysis}

Data referring to sand flies were worked from the calculation of vector proportions according to location and period of capture, species, sex and existence or not of Leishmania DNA.

The calculation of the DNA detection rate (DR), defined by the presence of amplified fragments of Leishmania spp. in samples, calculated as the number of positive tests divided by the total number of samples and multiplied by 100 .

Analyzes involving calculations of proportions were performed using the Microsoft ${ }^{\circledR}$ Office Excel 2016 program, after the abnormality test, comparisons between proportions performed were obtained using the $Z$ test and correlation analyzes were performed using Spearman's correlation tabulated in Microsoft $\circledast$ Office Excel 2016 and analyzed in STATA ${ }^{1} 12$ and XLSTAT ${ }^{8} 15$. The interpretations were made adopting a significance level of $5 \%(a=0.05$ ).

\section{Results}

\subsection{Phlebotomines collected}


A total of 5,935 sand flies were collected, distributed among 32 species, with 1,993 (33.58\%) specimens captured in the PERD [5] (Souza et al., 2015) and the majority, $3,942(66.42 \%)(z=37,38 ; p<0.0001)$ was collected in the AUT households. The male/female ratio was 0.64 in the PERD (776/1.217) and 0.74 in the urban area (1.250/2,692). Species richness was higher in the PERD (27 spp.) than in the urban area (19 spp.), however the abundance of species collected was lower in the PERD with $44.46 \%$ (166.08 specimens/trap) in relation to the urban area with $55.54 \%(207.47$ specimens/trap) $(z=3.02 ; p<0.003)$. The most abundant species, adding those collected from the two areas, were Nyssomyia whitmani (45.70\%), Nyssomyia intermedia (15.91\%) (Table 1), Lutzomyia longipalpis was found only in the AUT. 
Table 1

Sand flies captured in the Rio Doce State Park and urban area of Timóteo-MG, according to sex and place of capture, 2012-2014.

\begin{tabular}{|c|c|c|c|c|c|c|c|c|}
\hline \multirow[t]{2}{*}{ Species } & \multicolumn{3}{|c|}{ * Sand flies collected in PERD } & \multicolumn{3}{|c|}{ Sand flies collected in AUT } & \multirow[t]{2}{*}{ Total } & \multirow[t]{2}{*}{ (\%) } \\
\hline & Male & Female & Total & Male & Female & Total & & \\
\hline Lutzomyia sp. & 0 & 6 & 6 & 0 & 1 & 1 & 7 & 0,12 \\
\hline Brumptomyia sp. & 0 & 42 & 42 & 0 & 73 & 73 & 115 & 1,94 \\
\hline Br. avellari & 54 & 0 & 54 & 98 & 0 & 98 & 152 & 2,56 \\
\hline Br. nitzulescui & 40 & 0 & 40 & 4 & 0 & 4 & 44 & 0,74 \\
\hline Ev. tupynambai & 1 & 46 & 47 & 0 & 0 & 0 & 47 & 0,79 \\
\hline Ev. cortelezzii & 0 & 1 & 1 & 1 & 0 & 1 & 2 & 0,03 \\
\hline Ev. costalimai & 1 & 0 & 1 & 0 & 0 & 0 & 1 & 0,02 \\
\hline Ev. edwardsi & 0 & 4 & 4 & 0 & 0 & 0 & 4 & 0,07 \\
\hline Ev. lenti & 0 & 0 & 0 & 6 & 7 & 13 & 13 & 0,22 \\
\hline Ev. sallesi & 0 & 3 & 3 & 0 & 32 & 32 & 35 & 0,59 \\
\hline Ev. termitophila & 1 & 4 & 5 & 0 & 4 & 4 & 9 & 0,15 \\
\hline Lu. longipalpis & 0 & 0 & 0 & 4 & 3 & 7 & 7 & 0,12 \\
\hline Mi. ferreirana & 20 & 1 & 21 & 0 & 0 & 0 & 21 & 0,35 \\
\hline Mi. capixaba & 0 & 45 & 45 & 0 & 4 & 4 & 49 & 0,83 \\
\hline Mi. oswaldoi & 0 & 3 & 3 & 0 & 0 & 0 & 3 & 0,05 \\
\hline Mi. quinquefer & 1 & 16 & 17 & 11 & 113 & 124 & 141 & 2,38 \\
\hline Mg. migonei & 16 & 48 & 64 & 25 & 91 & 116 & 180 & 3,03 \\
\hline Ny. whitmani & 16 & 75 & 91 & 837 & 1.784 & 2.621 & 2.712 & 45,70 \\
\hline Ny. intermedia & 141 & 85 & 226 & 214 & 504 & 718 & 944 & 15,91 \\
\hline Pi. bianchigalatiae & 0 & 1 & 1 & 0 & 1 & 1 & 2 & 0,03 \\
\hline Pi. fischeri & 3 & 41 & 44 & 21 & 23 & 44 & 88 & 1,48 \\
\hline Pi. misionensis & 0 & 5 & 5 & 0 & 0 & 0 & 5 & 0,08 \\
\hline Pi. pessoai & 0 & 3 & 3 & 15 & 4 & 19 & 22 & 0,37 \\
\hline Pr. choti & 198 & 183 & 381 & 9 & 31 & 40 & 421 & 7,09 \\
\hline Pa. shannoni & 0 & 2 & 2 & 0 & 0 & 0 & 2 & 0,03 \\
\hline Pa. aragaoi & 0 & 2 & 2 & 0 & 2 & 2 & 4 & 0,07 \\
\hline Pa. lanei & 0 & 7 & 7 & 0 & 0 & 0 & 7 & 0,12 \\
\hline Pa. lutziana & 0 & 7 & 7 & 0 & 1 & 1 & 8 & 0,13 \\
\hline Pa. pascalei & 97 & 59 & 156 & 2 & 1 & 3 & 159 & 2,68 \\
\hline Ps. carreirai & 28 & 143 & 171 & 1 & 6 & 7 & 178 & 3,00 \\
\hline Ps. davisi & 18 & 294 & 312 & 1 & 6 & 7 & 319 & 5,37 \\
\hline Ps. geniculatus & 0 & 4 & 4 & 0 & 0 & 0 & 4 & 0,07 \\
\hline Sc. sordellii & 2 & 20 & 22 & 0 & 0 & 0 & 22 & 0,37 \\
\hline Ty. longispina & 139 & 67 & 206 & 1 & 1 & 2 & 208 & 3,50 \\
\hline Total (\%) & 776 & 1.217 & 1.993 & 1.250 & 2.692 & 3.942 & 5.935 & 100,00 \\
\hline
\end{tabular}

\subsection{Molecular detection of Leishmania spp. DNA}


A total of 2,939 females of not fed sand flies were used in the Leishmania detection analysis, of these 370 (12.6\%) were captured in the PERD and 2,569 (87.4\%) in the AUT (Table 2). After PCR/ITS1 57 positive samples for Leishmania spp. were detected, being 6 collected at PERD and 51 in the urban area (Table 2).

Table 2

DNA detection rate of Leihsmania spp. in female sand flies according to species, collected in the Parque Estadual do Rio Doce and in the urban area of the Timóteo-MG, 2012-2014.

\begin{tabular}{|c|c|c|c|c|c|c|c|c|c|c|c|c|c|}
\hline \multirow[t]{2}{*}{ Species* } & \multicolumn{5}{|c|}{ Collections in PERD } & \multicolumn{5}{|c|}{ Collections in AUT } & \multicolumn{3}{|l|}{ Total } \\
\hline & $\begin{array}{l}\text { N. of } \\
\text { females\# }\end{array}$ & $\%$ & $\begin{array}{l}\text { Samples } \\
\text { positive }\end{array}$ & $\%$ & DR & $\begin{array}{l}\text { N. of } \\
\text { females\# }\end{array}$ & $\%$ & $\begin{array}{l}\text { Samples } \\
\text { positive }\end{array}$ & $\%$ & DR & $\begin{array}{l}\text { N. of } \\
\text { females \# }\end{array}$ & $\%$ & $\begin{array}{l}\text { Samples } \\
\text { positive }\end{array}$ \\
\hline $\begin{array}{l}\text { Lutzomyia } \\
\text { sp.๑ }\end{array}$ & 1 & 0.27 & 0 & - & - & 1 & 0.04 & 1 & - & - & 2 & 0.07 & 1 \\
\hline Ev. lenti & 0 & 0.00 & 0 & 0.00 & 0.00 & 7 & 0.27 & 1 & 1.96 & 14.29 & 7 & 0.24 & 1 \\
\hline Ev. sallesi & 0 & 0.00 & 0 & 0.00 & 0.00 & 32 & 1.25 & 1 & 1.96 & 3.13 & 32 & 1.09 & 1 \\
\hline $\begin{array}{l}\text { Mg. } \\
\text { migonei }\end{array}$ & 26 & 7.03 & 0 & 0.00 & 0.00 & 91 & 3.54 & 3 & 5.88 & 3.30 & 117 & 3.99 & 3 \\
\hline $\begin{array}{l}\text { Ny. } \\
\text { whitmani }\end{array}$ & 23 & 6.22 & 0 & 0.00 & 0.00 & 1,784 & 69.44 & 37 & 72.55 & 2.07 & 1,807 & 61.61 & 37 \\
\hline $\begin{array}{l}\mathrm{Ny} \text {. } \\
\text { intermedia }\end{array}$ & 53 & 14.32 & 0 & 0.00 & 0.00 & 504 & 19.62 & 7 & 13.73 & 1.39 & 557 & 18.99 & 7 \\
\hline Ps. davisi & 154 & 41.62 & 2 & 33.33 & 1.30 & 6 & 0.23 & 0 & 0.00 & 0.00 & 160 & 5.46 & 2 \\
\hline Pr. choti & 105 & 28.38 & 4 & 66.67 & 3.81 & 31 & 1.21 & 0 & 0.00 & 0.00 & 136 & 4.64 & 4 \\
\hline $\begin{array}{l}\text { Mi. } \\
\text { quinquefer }\end{array}$ & 8 & 2.16 & 0 & 0.00 & 0.00 & 113 & 4.40 & 1 & 1.96 & 0.88 & 121 & 4.13 & 1 \\
\hline Total & 370 & 100.00 & 6 & 100.00 & 1.62 & 2,569 & 100.00 & 51 & 100.00 & 1.94 & 2,939 & 100.20 & 57 \\
\hline
\end{tabular}

* Female sand fly species positive by PCR/ITS1. DR - DNA Detection Rate.

\# Only female sand flies used in the molecular study for the detection of Leishmania spp. DNA.

The DNA detection rate was not calculated as it was not possible to define the species.

The DNA detection rate was $1.62 \%$ for PERD and $1.94 \%$ for AUT. The species Psychodopygus davisi (1.30\%) Pressatia choti (3.81\%) were the only ones detected with Leishmania sp. DNA in the PERD. In relation to the AUT samples, the vector species with the highest DNA detection rate was Migonemyia migonei (3.30\%), Nyssomyia whitmani (2.07\%) and Nyssomyia intermedia (1.39\%) (Table 2).

A total of 49 PCR/ITS1 positive samples were cloned, sequenced and deposited in GenBank under numbers MT707557 - MT707605. Of the 49 samples sequenced, two (4.08\%) Pressatia choti were collected at PERD, with detection of Leishmania braziliensis DNA. The other samples were collected at the AUT, the species with the highest number of females detected with Leishmania DNA was Nyssomyia whitmani with 35 (71.43\%) samples identified with the presence of Leishmania braziliensis DNA, followed by Nyssomyia intermedia with 06 (12, 24\%) samples with the presence of Leishmania braziliensis DNA. Also in the AUT, one specimen of Migonemyia migonei and one of Nyssomyia intermedia with the presence of Leishmania amazonensis DNA and a specimen of Nyssomyia intermedia with the presence of Leishmania guyanensis DNA were identified (Table 3). 
Table 3

Identification of Leishmania spp. DNA present in female sand flies collected, according to collection area, Timóteo$M G, 2012-2014$.

\begin{tabular}{|llllllll|}
\hline Leishmania species & Sand flies & \multicolumn{3}{l}{ Number of samples collected } & & \\
\cline { 3 - 7 } & & AUT & $\%$ & PERD & $\%$ & Total & $\%$ \\
\hline Leshmania (Viannia) guyanensis & Ny. intermedia & 1 & 2.13 & 0 & 0.00 & 1 & 2.04 \\
\hline Leishmania (Leishmania) amazonensis & Mg. migonei & 1 & 2.13 & 0 & 0.00 & 1 & 2.04 \\
\hline Leishmania (Viannia) braziliensis & Mi. quinquefer & 1 & 2.13 & 0 & 0.00 & 1 & 2.04 \\
\hline Leishmania (Viannia) braziliensis & Lutzomyia sp. & 1 & 2.13 & 0 & 0.00 & 1 & 2.04 \\
\hline Leishmania (Viannia) braziliensis & Pr. choti & 0 & 0.00 & 2 & 100.00 & 2 & 4.08 \\
\hline Leishmania (Viannia) braziliensis & Ev. sallesi & 1 & 2.13 & 0 & 0.00 & 1 & 2.04 \\
\hline Leishmania (Viannia) braziliensis & Mi. migonei & 1 & 2.13 & 0 & 0.00 & 1 & 2.04 \\
\hline Leishmania (Viannia) braziliensis & Ny. whitmani & 35 & 74.47 & 0 & 0.00 & 35 & 71.43 \\
\hline Leishmania (Viannia) braziliensis & Ny. intermedia & 6 & 12.77 & 0 & 0.00 & 6 & 12.24 \\
\hline Total & & 47 & & $\mathbf{2}$ & & 49 & \\
\hline
\end{tabular}

\subsection{Blood source study}

PCR/CytB was performed on 44 female fed sand flies (Table 4), 39 (88.6\%) were collected in the AUT and 5 (11.4\%) in the PERD, followed by sequencing of the samples and deposited in GenBank under numbers MT796689 - MT796732. Amplified material from six species was verified, one species of bird Gallus gallus (chicken) and the other five species of mammals: Dasyprocta leporina (acutia), Dasypus novemcinctus (armadillo), Sphiggurus villosus (hedgehog), Sus scrofa (pig) and Homo sapiens (Table 4).

Table 4

Results of blood source identification in naturally fed female sand flies collected in the municipality of Timóteo-MG, 2012-2014.

\begin{tabular}{|llllll|}
\hline \multirow{2}{*}{ Sand flies } & Fonte alimentar & \multicolumn{4}{c}{ Number of samples collected } \\
\cline { 3 - 6 } & & AUT & PERD & Total & $\%$ \\
\hline Presatia choti & Dasyprocta leporina & - & 1 & 1 & 2.27 \\
\hline Psychodopygus davisi & Dasypus novemcinctus & - & 1 & 1 & 2.27 \\
\hline Psychodopygus davisi & Sphiggurus villosus & - & 1 & 1 & 2.27 \\
\hline Pintomyia fischeri & Gallus gallus & 1 & - & 1 & 2.27 \\
\hline Nyssomyia intermedia & Homo sapiens & 2 & 2 & 4 & 9.09 \\
\hline Nyssomyia intermedia & Gallus gallus & 4 & - & 4 & 9.09 \\
\hline Nyssomyia intermedia & Sus scrofa & 2 & - & 2 & 4.55 \\
\hline Migonemyia migonei & Gallus gallus & 7 & - & 7 & 15.91 \\
\hline Nyssomyia whitmani & Homo sapiens & 4 & - & 4 & 9.09 \\
\hline Nyssomyia whitmani & Gallus gallus & 10 & - & 10 & 22.73 \\
\hline Nyssomyia whitmani & Sus scrofa & 9 & - & 9 & 20.45 \\
\hline Total & & 39 & $\mathbf{5}$ & $\mathbf{4 4}$ & $\mathbf{1 0 0 . 0}$ \\
\hline
\end{tabular}

Among the specimens of female sand flies collected in the PERD, genetic material of Dasyprocta leporina, Dasypus novemcinctus, Sphiggurus villosus and Homo sapiens was identified. Regarding the 39 female sand flies fed collected at the AUT, a blood source was identified by Homo sapiens ( $\mathrm{n}=6 / 15.4 \%$ ), Gallus gallus $(\mathrm{n}=22 / 56.4 \%)$ and Sus scrofa $(\mathrm{n}=11 / 28.2 \%)$.

\section{Discussion}

\subsection{Phlebotomines collected}

The large number of specimens collected in the AUT may be related to the ability of these sand flies to adapt to anthropogenic environments, and the availability of blood and ideal shelter for the maintenance and survival of sand flies in the AUT, corroborating the work described by Sanguinette et al. (2015) 
[14] in the state of Minas Gerais.

Among the most collected species Nyssomyia intermedia and Migonemyia migonei are already described species with a high degree of anthropophily and with a high capacity to adapt to the environment modified by man [15-17]. Nyssomyia whitmani, on the other hand, has been shown to be a species with greater tendency to the transitional environment, and adapting to the peridomicile [18, 19]. The large number of these species collected in Timóteo demonstrates that they are already adapted to the city's urban environment. And the fact that these species are of medical importance requires special attention from health authorities, such information can help in taking preventive and control measures.

Although it is not the first record of Lutzomyia longipalpis in the study area, it is important to emphasize that the capture of Lutzomyia longipalpis is not common, since in previous studies it was not identified in the urban area of the municipality $[6,9]$ which draws attention to the beginning of a possible adaptation of Lutzomyia longipalpis in the municipality, as demonstrated in Mato Grosso do Sul by Oliveira et al. (2006) [20].

\subsection{Detection of Leishmania spp. DNA}

Psychodopygus davisi and Pressatia choti were the only ones detected with Leishmania DNA in PERD despite having a low detection rate. Special attention should be given especially when dealing with wild areas, as there is already a record of the participation of Pressatia choti in the transmission of Leishmania in the Amazon region [21-23] and identification of Psychodopygus davisi with Leishmania braziliensis infection in the state of Acre [24]. It is important to point out that there were records of TL cases of professionals and visitors after incursions on this trail of the PERD (unpublished data).

This is the first record of Leishmania braziliensis DNA detection in Pressatia choti. This species is not found among the vector species of Leishmania, however, it was the predominant species among those collected in the PERD (19.12\%). These findings raise the hypothesis that this species may participate as a vector of Leishmania braziliensis in the PERD.

Among the species with the presence of Leishmania DNA in the AUT, detection rates were higher than those reported in other studies. Oliveira-Pereira et al. (2006) [25] in the state of Maranhão, found a rate of $0.80 \%$ in females of Nyssomyia whitmani. Neitzke-Abreu et al. (2014) [26] worked in endemic regions of TL in the state of Paraná and reported a detection rate of 1.12\% in Nyssomyia whitmani. Carvalho et al. (2008) [27], in a study carried out in the state of Minas Gerais, found a rate of $0.83 \%$ in Nyssomyia whitmani.

Despite the large number of females collected from the Nyssomyia whitmani species, the highest rate of Leishmania DNA detection was from Migonemyia migonei, a species already recognized as a vector and which may be actively participating in the transmission cycle of Leishmania in the municipality, together with Nyssomyia whitmani and Nyssomyia intermedia. It is possible, therefore, to suggest that these species are responsible for the transmission of Leishmania in the municipality.

Regarding the species Evandromyia lenti (DNA detection rate of 14.29\%), Evandromyia sallesi (DNA detection rate of 3.13\%) and Micropygomyia quinquefer (DNA detection rate of $0.88 \%$ ), all had only a positive sample, but as they presented a low number of captured specimens, the result of the DNA detection rate was high. This does not indicate that these species are responsible for the transmission of Leishmania in the area. However, we should not ignore these findings even though species are not reported as vectors. There are even other studies recording the natural infection of these species, which is not enough to define them as vectors.

Micropygomyia quinquefer has already been registered with Leishmania braziliensis DNA in a study carried out in Mato Grasso do Sul [28]. However, this information should be viewed with caution, as this species belongs to a group of sand flies in which females feed on cold-blooded animals [29].

There has already been detection of Leishmania sp. DNA in Evandromyia lenti and Evandromyia sallesi in the state of Minas Gerais [30-32]. In Evandromyia sallesi, natural infection by Leishmania infantum [33].

The result obtained from Nyssomyia intermedia, found in urban areas with Leishmania guyanensis DNA, should be treated with caution, since the region found does not belong to the geographic distribution region of this species, although there is already a record of this parasite species in three sand fly species in the north of Minas Gerais Therefore, there is a need for studies that can better demonstrate the circulation of Leishmania guyanensis in this region.

This is the first report of de Migonemyia migonei, a specimen collected in urban areas, with Leishmania amazonensis DNA. Experimental infection data have shown that infection by Leishmania amazonensis in Migonemyia migonei is possible [34, 35]. It is important to mention that Leishmania amazonensis have been recorded in Minas Gerais in sand flies and dogs [31, 36-38]. Therefore, the present study suggests that Leishmania amazonensis may also be a possible agent of leishmaniasis in the municipality of Timóteo.

Our results show that in the municipality of Timóteo there are at least three species of Leishmania spp. with the possibility of maintenance of the life cycle, being able to have direct participation in cases of leishmaniasis both in the urban area and in the wild area (PERD) of the city, but with the possibility of different vectors between the two areas.

\subsection{Blood source study}

Among the samples collected in PERD, only the female sand fly with blood of Homo sapiens was not collected in the inner area of the PERD, this female sand fly was identified as Nyssomyia intermedia, collected near the forest, at a distance of 300 meters from the edge from the forest, the others were collected in more internal areas, at a distance of more than 1,000 meters from the edge of the forest. It is interesting to note that the edge of the forest is an area close to human habitation and the presence of human beings in this region is intense, which justifies the identification of a blood source in female Nyssomyia intermedia as Homo sapiens. 
Also in PERD, the DNA of Dasyprocta leporina was identified in fed Pressatia choti females, while Dasypus novemcinctus and Sphiggurus villosus were identified in the blood of Psychodopygus davisi females. Due to the finding of Leishmania DNA in these sand fly species, the hypothesis that these mammals could act as Leishmania reservoirs in the PERD. Previous studies have already reported the presence of natural infection in these species of mammals, as in the case described by Lainson et al., (1981) [39] in a study developed in the state of Pará, reporting the presence of natural infection in Dasypus novemcinctus. Paiz et al. (2015) [40] performing a study in Botucatu state of São Paulo, with serological analysis detected anti-Leishmania spp. in Sphiggurus villosus.

The presence of a blood source by Homo sapiens in the urban area should be seen as normal, since the fed female sand flies were collected in the peridomicile. These data are in agreement with studies carried out by Carvalho et al. (2017) [32] who observed that sand flies from urban areas feed to a greater extent on dogs, chickens and humans. In the present work, studies indicate a lower proportion of Homo sapiens compared to Gallus gallus ( $\mathrm{z}=4.276 \mathrm{p}<$ $0.0001)$ and Sus scrofa $(z=1.715 p<0.05)$.

The role of birds in the epidemiology of leishmaniasis has been widely discussed, even though they are considered refractory to Leishmania infection. Tanure et al., (2015) [41] in the municipality of Governador Valadares verified that 43.6\% of Lutzomyia longipalpis fed in Gallus gallus. Sus scrofa, on the other hand, as a mammal, draws attention to a possible reservoir in urban areas having already been found infected by Leishmania sp. in Maranhão [42]. Baum et al. (2015) [43], using molecular analysis in females of Nyssomyia intermedia collected in the state of Paraná, verified the presence of samples with DNA of Sus scrofa. The role of Gallus gallus and Sus scrofa, even though the latter is not proven as Leishmania reservoirs, are important, since these species help to maintain the life cycle of sand flies in urban areas. The results obtained from the source of infection are essential to help the adoption of more effective measures to prevent and control leishmaniasis.

\section{Conclusion}

With the study, it was possible to identify the presence of three species of Leishmania in the city, Leishmania braziliensis, Leishmania amazonensis, Leishmania guyanensis, with Leishmania braziliensis possibly being the main responsible for the cases of tegumentary leishamaniasis in the region, since this species was identified in the more diverse samples collected.

The large number of Pressatia choti and Psychodopygus davisi in the wild area (PERD), added to the presence of Leishmania braziliensis in Pressatia choti suggests a possible participation of these species in the Leishmania cycle in the PERD area. While in urban areas the large number of Nissomyia whitmani, associated with Leishmania braziliensis make this species the main vector in the municipality. These results help the health surveillance service to adopt more effective measures, helping to prevent and control tegumentary leishmaniasis in the municipality, such as, for example, prioritizing the regions where there was a greater number of sand flies vectors and intensifying preventive campaigns with the PERD and the homes in the surroundings areas of the Park. And finally, the results obtained from the study of blood source, with the participation of Gallus gallus and Sus scrofa, are important and can be essential to help the adoption of more effective measures for the prevention and control of leishmaniasis.

\section{Abbreviations}

TL: Tegumentary Leishmaniasis; VL: Visceral Leishmaniasis; WHO: World Health Organization; IBGE: Instituto Brasileiro de Geografia e Estatistica; PERD: Parque Estadual do Rio Doce; AUT: Urban area of the municipality of Timóteo; DNA: Deoxyribonucleic Acid; ITS1: Internal Transcribed Spacer 1; PCR: ; CytB: Cytochrome B; CAPES: Coordenação de Aperfeiçoamento de Pessoal de Nível Superior; CNPq: Conselho Nacional de Desenvolvimento Científico e Tecnológico; SISBIO: Sistema de Autorização e Informação em Biodiversidade; IEF /MG: Instituto Estadual de Florestas de Minas Gerais; Br.: Brumptomyia; Ev.: Evandromyia; Lu.: Lutzomyia; Mi.: Micropygomyia; Mg.: Migonemyia; Ny.: Nyssomyia; Pi.: Pintomyia; Pa.: Psathyromyia; Pr.: Pressatia; Ps.: Psychodopygus; Sc.: Sciopemyia; Ty.: Trichopygomyia.

\section{Declarations}

\section{Financing}

The study was financed by the Coordenação de Aperfeiçoamento de Pessoal de Nível Superior - CAPES for the study of the CFS, and the project was financed by the Conselho Nacional de Desenvolvimento Científico e Tecnológico - CNPq (302701/2016-8), Fundação de Amparo à Pesquisa do Estado de Minas Gerais (FAPEMIG-PPM-00792-18) and the Ministerio da Saúde (Project 9656 - FUNARBE/UFV/MS).

Funding agencies played no role in study design, or data collection, analysis, and interpretation. They played no role in writing the manuscript.

\section{Ethical approval}

For the captures of sand flies, a permanent license for the collection of zoological material under n. 15.237-2 of the Sistema de Autorização e Informação em Biodiversidade - SISBIO, granted by the Ministerio do Meio Ambiente the license to carry out research in a conservation unit, under number $058 / 12$, granted by the Instituto Estadual de Florestas de Minas Gerais - IEF /MG

\section{Author statement CRediT}

CFS: Conceptualization, Methodology, Research, Data Collection, Data Analysis, Original Draft Writing, Article Review and Editing. CAS: Research and Data Collection. PDB, JDAF and RPB: Conceptualization, Methodology, Article Review and Editing, Project Management, Acquisition of Funding. RPB: Project Administration. 
All authors read and approved the final manuscript.

\section{Data availability}

All data generated or analyzed during this study is included in this published article and its supplementary information files.

\section{Declaration of conflicting interests}

The authors declare that they are not aware of competing financial interests or personal relationships that may have influenced the work reported in this article.

\section{Recognitions}

We would like to thank the owners of the homes where the studies took place for allowing us access to their properties and the Municipal Health Department and the Parque Estadual do Rio Doce for granting us authorization and supporting this study in Timóteo.

\section{References}

1. Chance ML. The biochemical and immunotaxonomy of Leishmania. In: Chang/Gray (eds) Elsevier Science Publishing Company, USA. 1985:93-110.

2. World Health Organization. Leishmaniasis.. 2021. Available at: https://www.who.int/health-topics/leishmaniasis\#tab=tab_1. Accessed 21 August 2021.

3. Brasil. Epidemiologia e Morbidades. Ministério da Saúde, 2021. Available at: http://www2.datasus.gov.br/DATASUS/index.php. Accessed 21 August 2021.

4. Instituto Brasileiro de Geografia e Estatística. Cidades. 2021. Available at: https://cidades.ibge.gov.br/. Accessed 21 August 2021.

5. Souza CF, Brazil RP, Bevilacqua PD, Andrade Filho JA. The phlebotomine sand flies fauna in Parque Estadual do Rio Doce, Minas Gerais, Brazil. Parasit. Vectors. 2015;8:619. https://doi.org/10.1186/s13071-015-1227-1.

6. Andrade Filho JD, Carneiro APS, Lima MLN, Santiago RM, Gama MA, Santos CA, Falcão AL, Brazil RP. Flebotomíneos de Timóteo, Estado de Minas Gerais, Brasil (Diptera: Psychodidae). Cad Saúde Pública. 1997;13(4):767-70. https://doi.org/10.1590/S0102-311X1997000400019.

7. Souza CF, Borges MAZ. Ocorrência de Lutzomyia longipalpis (Lutz \& Neiva, 1912) (Diptera, Psychodidae) em Timóteo, Minas Gerais, Brasil. Cad. Saúde Pública. 2008;24:1454-1455. https://doi.org/10.1590/S0102-311X2008000600026.

8. Souza CF, Borges MAZ, Andrade AJ. Contribution to the Knowledge of the Phlebotomine Sand Flies Fauna (Diptera: Psychodidae) of Timóteo Municipality, Minas Gerais, Brazil. Neotrop Entomol. 2009;38:267-271. https://doi.org/10.1590/S1519-566X2009000200016.

9. Souza CF, Quaresma PF, Andrade Filho JD, Bevilacqua PD. Phlebotomine Fauna in the Urban Area of Timóteo, State of Minas Gerais, Brazil. Acta Tropica. 2014;134:72-79. http://dx.doi.org/10.1016/j.actatropica.2014.02.019.

10. Galati EAB. Morfologia e taxonomia. In: Rangel, E.F., Lainson, R. Flebotomíneos do Brasil. Fiocruz, Rio de Janeiro. 2003:23-206.

11. Marcondes CB. A proposal of generic and subgeneric abbreviations for phlebotomine sandflies (Diptera: Psychodidae: Phlebotominae) of the word. Entomol. News. 2007;18:351-356.

12. Schönian G, Nasereddin A, Dinse N, Schweynoch C, Schallig HD, Presber W, Jaffe CL. PCR diagnosis and characterization of Leishmania in local and imported clinical samples. Diagn Microb Infec Disease. 2003;47:349-358. https://doi.org/10.1016/S0732-8893(03)00093-2.

13. Steuber S, Abdel-Rady A, Clausen PH. PCR-RFLP analysis: a promising technique for host species identification of blood meals from tsetse flies (Diptera: Glossinidae). Parasitol Res. 2005;97:247-254. https://doi.org/10.1007/s00436-005-1410-y.

14. Sanguinette CC, da Silva DF, Stumpp RG, Rêgo FD, Tonelli GB, Tanure A, Gontijo CM, Andrade Filho JD. Comparison of the phlebotomine (Diptera: Psychodidae) fauna of urban, transitional, and wild areas in northern Minas Gerais, Brazil. Parasit Vectors.

2015;8(1):428. https://doi.org/10.1186/s13071-015-1003-2.

15. Rangel EF, Souza NA, Wermelinger ED, Azevedo ACR, Barbosa AF, Andrade CA. Flebótomos de Vargem Grande, Foco de Leishmaniose Tegumentar no Estado do Rio de Janeiro. Mem Inst Oswaldo Cruz. 1986;81(3):347-349. https://doi.org/10.1590/S0074-02761986000300013.

16. Gontijo CMF, Silva ES, Fuccio MB, Sousa MCA, Pacheco RS, Dias ES, Andrade Filho JD, Brazil RP, Melo MN. Epidemiological studies of an outbreak of cutaneous Leishmaniases in the Rio Jequitinhonha Valley, Minas Gerais, Brazil. Acta Tropica. 2002;81(2):143-150. https://doi.org/10.1016/S0001706X(01)00205-4.

17. Andrade Filho JD, Galati EAB, Falcão AL. Ny. intermedia (Lutz \& Neiva, 1912) and Ny. neivai (Pinto, 1926) (Diptera: Psychodidae: Phlebotominae) geographical distribution and epidemiological importance. Mem Inst Oswaldo Cruz. 2007;102(4):481-487. https://doi.org/10.1590/S0074276200700500003.

18. Aguiar GM, Medeiros WM. Distribuição regional e habitats das espécies de flebotomíneos do Brasil, In: Rangel EF, Lainson R. Flebotomíneos no Brasil, Fiocruz, Rio de Janeiro. 2003; 207-256.

19. Brazil RP, Brazil BG. Vetores na Leishmaniose Tegumentar Americana. In: Conceição-Silva F, Alves CR. Leishmaniose do continente americano. Fiocruz, Rio de Janeiro. 2014;193-200.

20. Oliveira AG, Galati EAB, Oliveira O, Oliveira GR, Espindola IAC, Dorval MEC, Brazil RP. Abundance of Lutzomyia longipalpis (Diptera: Psychodidae: Phlebotominae) and urban transmission of visceral leishmaniasis in Campo Grande, State of Mato Grosso do Sul, Brazil. Mem Inst Oswaldo Cruz. 2006;101(8):869-874. https://doi.org/10.1590/S0074-02762006000800008. 
21. Rangel EF, Lainson R. Transmissores de Leishmaniose Tegumentar Americana. In: Rangel, E.F., Lainson, R. Flebotomíneos do Brasil, Fiocruz, Rio de Janeiro. 2003;257-274.

22. Gil LHS, Basano SA, Souza AA, Silva MGS, Barata I, Ishikawa E, Shaw J. Recent observations on the sand fly (Diptera: Psychodidae) fauna of the State of Rondônia, Western Amazônia, Brazil: the importance of Psychdopygus davisi as a vector of zoonotic cutaneous leishmaniasis. Mem Inst Oswaldo Cruz. 2003;98(6):751-755. https://doi.org/10.1590/S0074-02762003000600007.

23. Dantas-Torres F, Sales KGS, Miranda DEO, da Silva FJ, Figueredo LA, de Melo FL, de Brito MEF, Andrade MS, Brandão-Filho SP. Sand fly population dynamics and cutaneous leishmaniasis among soldiers in an Atlantic forest remnant in northeastern Brazil. PLoS Negl Trop Dis. 2017;11(2):e0005406. https://doi.org/10.1371/journal.pntd.0005406.

24. de Ávila MM, Brilhante AF, de Souza CF, Bevilacqua PD, Galati EAB, Brazil RP. Ecology, feeding and natural infection by Leishmania spp. of phlebotomine sand flies in an area of high incidence of American tegumentary leishmaniasis in the municipality of Rio Branco, Acre, Brazil. Parasit Vectors. 2018;11(64):1-12. https://doi.org/10.1186/s13071-018-2641-y.

25. Oliveira-Pereira YN, Rebelo JMM, Moraes JLP, Pereira SRF. Diagnóstico molecular da taxa de infecção natural de flebotomíneos (Psychodidae, Lutzomyia) por Leishmania sp. na Amazônia maranhense. Rev Soc Bras Med Trop. 2006;39(6):540-543. https://doi.org/10.1590/S0037-86822006000600005.

26. Neitzke-Abreu HC, Reinhold-Castro KR, Venazzi MS, Scodro RBL, Dias-Sversutti AC, Silveira TGV, Teodoro U, Lonardoni MVC. Detection of Leishmania (Viannia) in Ny. neivai and Ny. whitmani by Multiplex Polymerase Chain Reaction, in southern Brazil. Rev Inst Med Trop de São Paulo. 2014;56(5): 391395. https://doi.org/10.1590/S0036-46652014000500004.

27. Carvalho GML, Andrade Filho JD, Falcão AL, Rocha Lima AC, Gontijo CM. Naturally Infected Lutzomyia Sand Flies in a Leishmania-Endemic Area of Brazil. Vector Borne Zoonotic Dis. 2008; 8(3):407-14. https://doi.org/10.1089/vbz.2007.0180.

28. Paiva BR, Oliveira AG, Dorval ME, Galati EA, Malafronte RS. Species-specific identification of Leishmania in naturally infected sand flies captured in Mato Grosso do Sul State, Brazil. Acta Tropica. 2010;115(1-2):126-130. https://doi.org/10.1016/j.actatropica.2010.02.013.

29. Deane LM, Deane MP. Observações sobre abrigos e criadouros de flebótomos no Noroeste do estado do Ceará. Rev Bras Malariología Doenças Trop. 1957; 9:225-246.

30. Margonari C, Soares RP, Andrade-Filho JD, Xavier DC, Saraiva L, Fonseca AL, Silva RA, Oliveira ME, Borges EC, Sanguinette CC, Melo MN. Phlebotomine Sand Flies (Diptera: Psychodidae) and Leishmania Infection in Gafanhoto Park, Divinópolis, Brazil. J. Med. Entomol. 2010;47:1212-

1219. https://doi.org/10.1603/ME09248.

31. Rêgo FD, Rugani JM, Shimabukuro PH, Tonelli GB, Quaresma PF, Gontijo CM. Molecular Detection of Leishmania in Phlebotomine Sand Flies (Diptera: Psychodidae) from a Cutaneous Leishmaniasis Focus at Xakriabá Indigenous Reserve, Brazil. PLoS One.

2015;10:e0122038. https://doi.org/10.1371/journal.pone.0122038.

32. Carvalho GML, Rêgo FD, Tanure A, Silva AC.P., Dias, T.A., Paz, G.F., Andrade Filho, J.D. Bloodmeal identification in fieldcollected sand flies from Casa Branca, Brazil, using the Cytochrome b PCR method. J Med Entomol. 2017;54(4):1049-1054. https://doi.org/10.1093/jme/tjx051.

33. Saraiva L, Carvalho GML, Gontijo CMF, Quaresma PF, Lima ACVMR, Falcão AL, Andrade Filho JD. Natural Infection of Lutzomyia neivai and Lutzomyia sallesi (Diptera: Psychodidae) by Leishmania infantum chagasi in Brazil. J Med Entomol. 2009;46(5):1159-1163. https://doi.org/10.1603/033.046.0525.

34. Nieves E, Pimenta PFP. Development of Leishmania (Viannia) braziliensis and Leishmania (Leishmania) amazonensisin the sand fly Lutzomyia migonei (Diptera: Psychodidae). J Med Entomol. 2000;37(1):34-140. https://doi.org/10.1603/0022-2585-37.1.134.

35. Nogueira PM, Guimarães AC, Assis RR, Sadlova J, Myskova J, Pruzinova K, Hlavackova J, Turco SJ, Torrecilhas ACT, Volf P, Soares RPP. Lipophosphoglycan polymorphisms do not affect Leishmania amazonensis development in the permissive vectors Lutzomyia migonei and Lutzomyia longipalpis. Parasit Vectors. 2017;10:608. https://doi.org/10.1186/s13071-017-2568-8.

36. Valdivia HO, Almeida LV, Roatt BM, Reis-Cunha JL, Pereira AA, Gontijo C, Fujiwara RT, Reis AB, Sanders MJ, Cotton JA, Bartholomeu DC. Comparative genomics of canine-isolated Leishmania (Leishmania) amazonensis from an endemic focus of visceral leishmaniasis in Governador Valadares, southeastern Brazil. Scientific Reports. 2017;7:40804. https://doi.org/10.1038/srep40804.

37. Cardoso MS, Bento GA, de Almeida LV, de Castro JC, Reis-Cunha JL, Barbosa VA, Souza CF, Brazil RP, Valdivia HO, Bartholomeu DC. Detection of multiple circulating Leishmania species in Lutzomyia longipalpis in the city of Governador Valadares, southeastern Brazil. PLoS One. 2019;14(2):e0211831. https://doi.org/10.1371/journal.pone.0211831.

38. Tanure A, Rêgo FD, Tonelli GB, Campos AM, Shimabukuro PHF, Gontijo CMF, Paz GF, Andrade-Filho JD. Diversity of phlebotomine sand flies and molecular detection of trypanosomatids in Brumadinho, Minas Gerais, Brazil. PLoS One. 2020;15(6):e0234445. https://doi.org/10.1371/journal.pone.0234445.

39. Lainson R, Shaw JJ, Ready PD, Miles MA, Póvoa M. Leishmaniasis in Brazil: XVI. Isolation and identification of Leishmania species from sandflies, wild mammals and man in north Para State, with particular reference to L. braziliensis guyanensis causative agent of "pian-bois". Trans R Soc Trop Med Hyg. 1981;75:530-536.

40. Paiz LM, Fornazari F, Menozzi BD, Oliveira GC, Coiro CJ, Teixeira CR, Campanucci da Silva VM, Donalisio MR, Langoni H. Serological Evidence of Infection by Leishmania (Leishmania) infantum (Synonym: Leishmania (Leishmania) chagasi) in Free-Ranging Wild Mammals in a Nonendemic Region of the State of São Paulo, Brazil. Vector Borne Zoonotic Dis. 2015;15(11):667-73. https://doi.org/10.1089/vbz.2015.1806.

41. Tanure A, Peixoto JC, Afonso MMS, Duarte R, Pinheiro AC, Coelho SVB, Barata RA. Identification of sandflies (Diptera: Psychodidae: Phlebotominae) blood meals in an endemic leishmaniasis area in Brazil. Rev Inst Med Trop São Paulo. 2015;57:321-324. https://doi.org/10.1590/S003656652015000400008.

42. Brazil RP, Nascimento NBSB, Macau RP. Infecção Natural do porco (Sus scrofa) por Leishmania em foco recente de Leishmaniose Tegumentar na Ilha de São Luis, Maranhão. Mem Inst Oswaldo Cruz. 1987; 82(1):145. https://doi.org/10.1590/S0074-02761987000100025. 
43. Baum M, Castroa EA, Pinto MC, Goulart TM, Bauraa W, Klisiowicz DR, Costa-Ribeiro MCIV. Molecular detection of the blood meal source of sand flies

(Diptera: Psychodidae) in a transmission area of American cutaneous leishmaniasis, Paraná State, Brazil. Acta Tropica. 2015;143:8-

12. https://doi.org/10.1016/j.actatropica.2014.11.006.

\section{Figures}

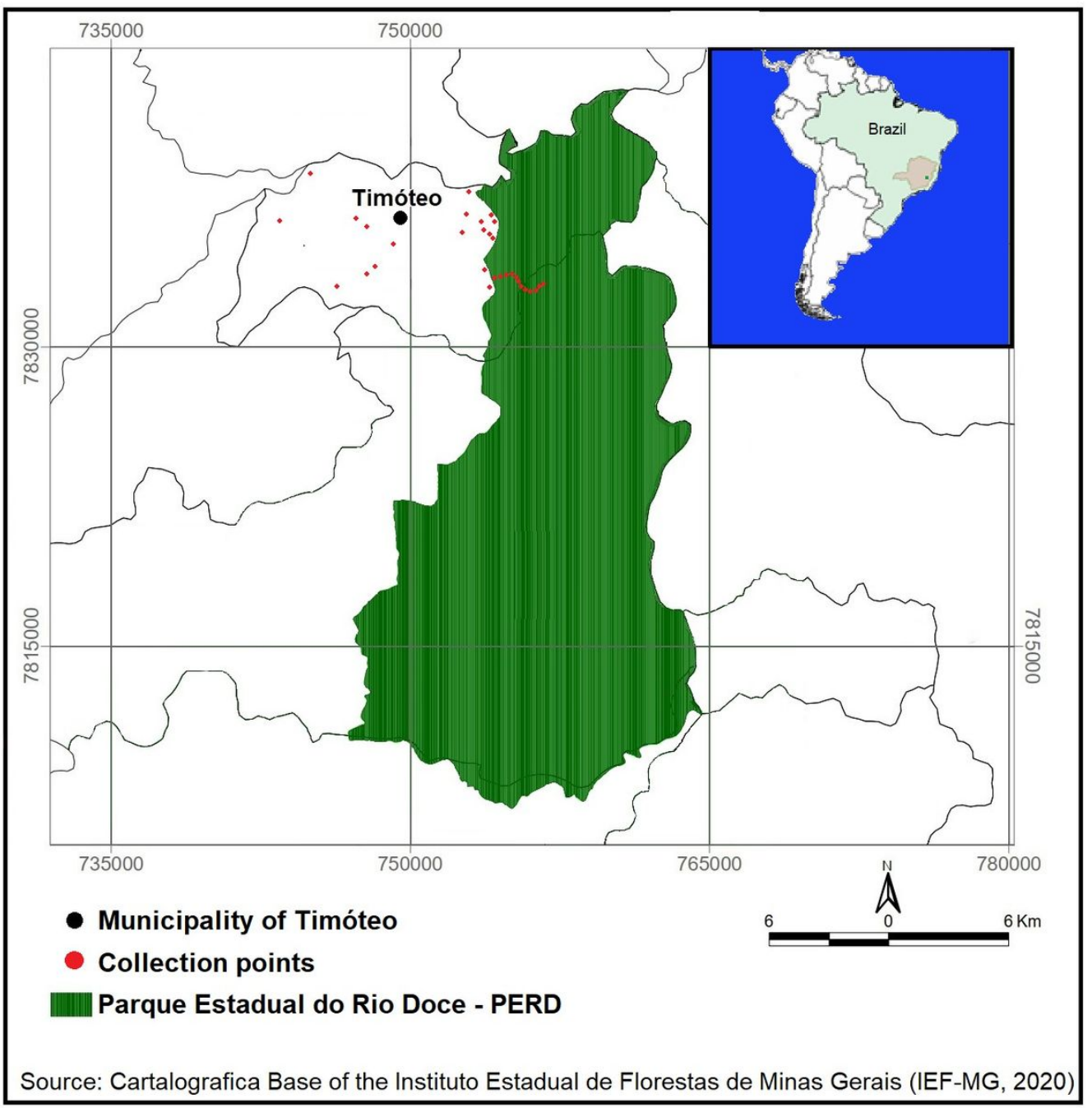

Figure 1

Study area map

\section{Supplementary Files}

This is a list of supplementary files associated with this preprint. Click to download.

- Graphicalabstractimage.jpg 